Revista aSEPHallus de Orientação Lacaniana

Núcleo Sephora de Pesquisa sobre o Moderno e o Contemporâneo

ISSN 1809 - $709 \mathrm{X}$

\title{
Experiência de saber e testemunho íntimo no encontro com os Escritos de Jacques Lacan
}

\author{
Antônio Teixeira \\ Doutor pelo Département de Psychanalyse de Paris VIII \\ Pós-Doutorado em Filosofia USP; Professor Adjunto do PPG em Psicologia da UFMG \\ Psicanalista, Membro da Escola Brasileira de Psicanálise \\ Membro da Associação Mundial de Psicanálise \\ Membro conselheiro da International Society of Psychoanalysis and Philosophy \\ E-mail: amteixeira@uol.com.br
}

Resumo: Convidado a testemunhar sobre seu encontro singular com os Escritos de J. Lacan, Antônio Teixeira afirma que não há apropriação teórica desse livro que possa ser dissociada do significado testemunhal de sua aquisição. No transcorrer deste artigo, o autor contextualiza a publicação dos Escritos em relação aos efeitos da recente fundação da Escola Francesa de Psicanálise e ao imperativo ético de restituir o sistema de pensamento em que o texto freudiano é deturpado em sua apropriação instrumental pelo contexto da egopsychology.

Palavras-chave: psicanálise; Escritos, testemunho; textos monográficos; estilo.

Expérience de savoir et témoignage intime dans la rencontre avec les Écrits de Jacques Lacan Invité à témoigner de sa rencontre unique avec les écrits de J. Lacan, Antônio Teixeira affirme qu'il n'y a pas d'appropriation théorique de ce livre qui puisse être dissociée du sens testimonial de son acquisition. Au cours de cet article, l'auteur contextualise la publication des Écrits par rapport aux effets de la récente fondation de l'École Française de Psychanalyse et à l'impératif éthique de restaurer le système de pensée dans lequel le texte freudien est déformé dans son appropriation instrumentale par la psychologie du moi.

Mots-clés: psychanalyse; Écrits; témoignage; textes monographiques; style.

\section{Experience of knowing and intimate testimony in the encounter with the Writings of Jacques Lacan}

Invited to testify about his unique encounter with the Writings of J. Lacan, Antônio Teixeira affirms that there is no theoretical appropriation of this book that can be dissociated from the testimonial meaning of its acquisition. In the course of this article, the author contextualizes the publication of the Writings in relation to the effects of the recent foundation of the French School of Psychoanalysis and to the ethical imperative of restoring the system of thought in which the freudian text is distorted in its instrumental appropriation by the context of the ego psychology.

Keywords: psychoanalysis; Writings, testimony; monographic texts; style. 


\section{Experiência de saber e testemunho íntimo no encontro com os Escritos de Jacques}

\section{Lacan $^{1}$}

\section{Antônio Teixeira}

Foi por volta, eu creio, do mês de junho desse ano que nosso colega Gilson Iannini nos interpelou com a ideia, que neste colóquio se concretiza, de se organizar as efemérides do cinquentenário dos Escritos de Jacques Lacan. Lembro-me de, naquela ocasião, ter abraçado a proposta com entusiasmo incontido; assim que li seu e-mail, precipitei-me a organizar o esboço desse encontro, onde acreditava poder enunciar os resultados de uma pesquisa que venho realizando sobre o significado desse gesto, assumido tardiamente por Lacan, de colocar-se em obra com a publicação dos Escritos. Mas houve de saída um desconforto: não havia consenso quanto à proposta de que alguém viesse teorizar sobre esse acontecimento. Para alguns, a ideia era que cada participante viesse não teorizar, mas testemunhar sobre seu encontro singular com os Escritos de J. Lacan, abrindo assim espaço para uma conversação acerca das incidências subjetivas dessa experiência.

Essa discordância inicial parecia inserir uma separação de propósito que nos dividia naquele período. Havia, por um lado, os que visavam ao projeto de uma transmissão testemunhal da experiência íntima de cada um, por oposição aos que optavam por uma visada mais epistêmica, mais orientada pela experiência universal de saber aberta com a leitura dessa publicação. Foi, aliás, a partir de tal divisão, por assim dizer, entre testemunhistas e epistemistas, que tentamos realizar a distribuição dos nomes entre as mesas, como se fosse possível opor leitura epistêmica e apropriação testemunhal dos Escritos. Se me interessa particularmente evocar isso aqui, é porque só tardiamente fui perceber o engano dessa divisão. Dei-me conta, já na véspera desse colóquio, de que essa divisão era ilusória, era um erro de perspectiva, uma separação que não existia. A ideia que eu gostaria de discutir é a de que não haveria, propriamente falando, uma divisão entre apropriação testemunhal dos Escritos e sua leitura epistêmica em razão do fato, que tentarei explicitar, de que não há apropriação teórica desse estranho livro que possa ser dissociada do significado testemunhal de sua aquisição.

Para esclarecer o que estou tentando dizer, gostaria de partir de um dado testemunhal que evoquei há algumas semanas no seminário da Biblioteca coordenado por minha amiga Márcia Rosa Luchina. Convidado a vir testemunhar, naquela ocasião, sobre a experiência de leitura de um livro que teria lido escondido, pensei, inicialmente, em declinar do convite, por lembrar que jamais precisei de ler um livro nessas circunstâncias. Diante da impossibilidade de falar de um livro que li escondido, ocorreu-me falar de minha experiência não exatamente de leitura, mas de arrebatamento por um objeto-livro, não de um livro que li escondido, mas de um livro que levei escondido há 30 anos, em 1986, o admirável objeto-livro que sempre foi para mim a versão original dos Escritos, de Jacques Lacan. Estudante sextanista de Medicina, sem recursos na grave crise dos anos 80, sentia-me 
irresistivelmente atraído por aquele estranho livro de que tanto se falava na Faculdade de Filosofia, exibido nas prateleiras externas da livraria que eu frequentava. Ciente de que, naquele tempo, ninguém dentre meus pares possuía tal relíquia, eu via a aquisição daquele livro como a conquista de um troféu. Mas sua apropriação não poderia ser o gesto banal de compra, ela teria que ser clandestina. Foi assim que, numa época em que ainda não havia etiquetas de alarme para aquele tipo de produto, coloquei o objeto-livro sob um jornal e saí nervoso e triunfante para fora da livraria.

Importante notar que por um longo período após essa apropriação indébita, quando já frequentava a residência de Psiquiatria do Instituto Raul Soares, eu conservava um objeto-livro que me encantava possuir, mas sem ter acesso a seu conteúdo. Já há alguns anos lia Freud, na tradução espanhola da Biblioteca Nueva, e meu interesse diletante pela Antropologia me permitia ter alguma ideia sobre o que era o Estruturalismo. Mas meu domínio indigente da língua francesa, somado à abissal ignorância da teoria lacaniana, tornava a leitura dos Escritos impeditiva. Foi somente dois anos mais tarde, quando comecei a frequentar os seminários do Simpósio do campo freudiano e o Mestrado em Filosofia da UFMG, que descobri nos autores pontífices as vias de entrada para a leitura dos Escritos. Foi assim que, nos cursos do professor Célio Garcia, me foi indicado estudar $O$ título da letra, de Nancy e Labarthe, ponte fundamental para a leitura de $A$ instância da letra no inconsciente, assim como o Desejo puro, de Bernard Baas, porta de entrada para "Kant com Sade", além dos artigos do jovem Jacques-Alain Miller, publicados nos Cahiers pour l'analyse, lanternas indispensáveis para iluminar a lógica dos textos escritos de Lacan.

Mas antes de ter acesso ao texto, havia, conforme estava dizendo, o estranho fascínio pelo objeto-livro que eu tinha em mãos: um grande volume de páginas sobriamente encadernadas em cobertura branca, contendo, na capa da frente, o único e discreto título: Écrits, em formato padrão, sobre o qual se divisava, em caracteres rubros, o nome não menos judicioso do seu autor: um certo Jacques Lacan. Somente alguns parágrafos na contracapa, de difícil apreciação. Nada de imagens, nenhum comentário de orelha, nenhuma manobra publicitária destinada a provocar o interesse do leitor. Um livro bizarro, desprovido de ornamentos, que tinha tudo para ser, como disse G. Iannini, um worstseller, um fracasso editorial: novecentas páginas de artigos esotéricos sem nenhuma concessão didática, inacessíveis tanto ao leitor iniciante quanto ao público leigo, redigidos no limite da inteligibilidade por alguém que, segundo me informavam, há muito desconfiava da facilidade enganosa da compreensão. Sua consagração foi, contudo, imediata, para a surpresa do próprio autor: cinco mil exemplares vendidos em quinze dias, cinquenta mil para a primeira edição, cento e vinte mil exemplares na edição de bolso...

Havia, portanto, ali, um enigma a se decifrar. Como entender esse surpreendente fenômeno de massa que subitamente elevou ao estatuto de obra monumental da cultura um conjunto de textos que, separadamente, estavam restritos ao círculo reservado de alguns poucos iniciados? Para buscar elucidá-lo, vale a pena tentar nos transpor para a situação francesa daquele momento, a fim de 
contextualizar o que ocorria quando Lacan se propôs lançar, em 1966, a coletânea de textos escritos que se tornou o seu magnum opus.

Sabemos, por exemplo, que, naquele período, todos os grandes autores da corrente estruturalista francesa já haviam publicado suas obras de referência. Lévi-Strauss já era conhecido por suas Estruturas elementares do parentesco e sua Antropologia Estrutural; Foucault, por sua História da loucura e seus estudos arqueológicos; Barthes, por seu Michelet e seus Elementos de Semiologia; e, um ano antes, em 1965, Althusser acabara de publicar o seu Ler o capital... Somente um certo Jacques Lacan permanecia alheio a esse movimento, dele se separando como pensador sem obra. Ocioso dizer que, naquela ocasião, nenhuma circunstância editorial o impedia de publicar a visão de conjunto de sua doutrina. O que estava em questão, nessa ausência de obra, não era uma impossibilidade contingente, relacionada, por exemplo, à carência de um editor; havia ali uma recusa meditada. A bem da verdade, a publicação dos Escritos jamais se colocou, para Lacan, como efeito de uma empolgação do autor. Essa publicação antes se situava, conforme salienta Éric Marty, no horizonte de uma reflexão pessimista sobre a ideia da assimilação da obra pela cultura, destinada, uma vez consumida, à lata de lixo da poubellication. O fazer-se obra não deriva, para Lacan, de algum tipo de voluntarismo particular. Se ele à obra consente, é antes, contrariado, em razão de uma escolha forçada, de uma decisão determinada pela força de um cálculo circunstancial.

O que estava em questão para Lacan, por ocasião da publicação dos Escritos, no final de 1966, eram os efeitos da ainda recente fundação da Escola Francesa de Psicanálise, criada em 1964, da qual ele assumiria explicitamente o encaminhamento tanto institucional quanto ético, político e epistêmico. A Escola Francesa de Psicanálise, renomeada como Escola Freudiana de Paris, se colocara, portanto, desde o seu início, como uma escola de orientação lacaniana. Lacan estava em vias de estabelecer a unidade de sua orientação no momento em que finalmente consentiu com a demanda de seu analisante, o editor François Wahl, que já há algum tempo insistia sem êxito em convencê-lo a publicar a coletânea selecionada de suas intervenções escritas.

A escolha forçada da obra se ligava, naquele momento, ao imperativo ético de restituir o sistema de pensamento em que o texto freudiano, deturpado em sua apropriação instrumental pelo contexto da ego-psychology, voltasse a revelar sua necessidade própria. A refundação da doutrina freudiana como um sistema dotado de necessidade interna implica, antes de tudo, separar o texto doutrinal de seu uso circunstancial, apartando o campo das proposições necessárias da teoria dos enunciados sem necessidade das opiniões. Restaurar o texto freudiano como um sistema de pensamento significa afastar o saber do rumor, o teorema do ponto de vista, a proposição necessária do discurso opinativo.

É nessa perspectiva que assumir a dimensão de obra, em seu sentido propriamente moderno, significa instaurar, em meio à multiplicidade geral da cultura, a unicidade de uma doutrina autônoma que desse múltiplo se diferencia, ali introduzindo uma superfície de refração. A obra tem por função separar o texto doutrinal dos enunciados do contexto cultural que dissipa o pensamento 
na pluralidade inconsistente das opiniões. Centrada em um sistema de nomeações que confere ao conjunto dos textos uma forma reconhecível, a obra realiza essa unicidade mediante a associação do nome do autor com o título materializado na publicação. O conceito gestado no interior de uma obra afirma-se, assim, como um conceito de autor, via de regra definido por um nome próprio, embora tal autoria possa também ser referida a uma coletividade reunida em torno de determinado paradigma. Falamos, portanto, do inconsciente freudiano, do engajamento de Sartre, do habitus de Bourdieu, da mais valia de Marx; mas também podemos nos referir à lógica de Port Royal, à álgebra comutativa de Bourbaki, e assim por diante.

É inexato, todavia, afirmar que toda produção autoral, seja ela coletiva ou individual, se determina invariavelmente como obra, se dermos ao termo de autoria o seu sentido mais específico. Eu posso referir-me, por exemplo, ao termo lalangue, valendo-me de um excelente artigo publicado por Ram Mandil, sem dizer que se trata de um conceito mandiliano. É possível ser autor de artigos ou mesmo de livros sem ser necessariamente autor de uma obra, como de fato acontece na grande maioria dos textos a que chamamos de monografias. Distintamente do autor de obra, o autor de monografia geralmente publica seus textos em periódicos destinados à difusão do saber já articulado a um determinado campo doutrinal. Embora Jean-Claude Milner reserve o termo "monografia" aos artigos relacionados à atividade científica, como aqueles que se publicam nos periódicos de física ou de biologia (Milner, 1995, p. 16), a mim me parece mais exato aplicar essa denominação a todo saber produzido no campo de uma prática discursiva previamente constituída. É nesse sentido que podemos chamar de monografias os textos divulgados, por exemplo, numa revista de arte ou de crítica literária, sem que seu conteúdo resulte necessariamente de algum tipo de atividade científica. A monografia é o texto que se realiza no espaço esotérico da obra, quando seu sistema já se encontra constituído como campo demonstrativo neutro.

Desculpem-me se trago aqui essas considerações, não é por mero desejo de teorizar. Elas nos ajudam a pensar sobre o que de fato ocorreu na mudança da monografia para a obra, por ocasião da publicação dos Escritos de Jacques Lacan. A discussão mais pormenorizada seria, todavia, demasiado extensa. Interessa-me enfatizar somente, como havia evocado há pouco, que a passagem da monografia à obra resulta, tanto no caso de Freud como no de Lacan, não de um querer voluntário, mas do gesto contrariado de uma decisão. No caso da constituição da obra freudiana, o célebre sonho da monografia botânica descrito na Traumdeutung vem revelar, no dizer de Jean-Claude Milner, a constatação melancólica, por parte de Freud, de sua necessidade de abandonar a via segura da monografia para perfurar, no contexto da cultura, um novo espaço que pudesse abrigar sua pesquisa. Era-Ihe necessário criar um campo específico para a doutrina que estava formulando, no momento em que o campo da monografia científica não oferecia mais lugar para a sua descoberta. O célebre verso de Virgílio "Flectere si nequeo Superos, Acheronta movebo", que Freud dispõe no frontispício de sua "Interpretação dos sonhos", reflete justamente esse 
imperativo: se não consigo convencer os representantes superiores da ciência (Flectere si nequeo Superos), moverei o campo subterrâneo da cultura (Acheronta movebo).

A conclusão, que todos conhecemos, é que a forma da obra triunfou, abrindo espaço para o texto psicanalítico no contexto da cultura, ainda que, como diz J.-C. Milner, a um altíssimo preço: a horda selvagem dos Jungs, Reichs, Ferenczis e Adlers, que Freud teve que suportar. Com o detalhe de que cada um deles queria se constituir como obra à parte, com sua corte de prosélitos, menos pela força de uma decisão do que pela banalidade do querer voluntário. Para assegurar a unidade do campo psicanalítico, evitando sua dispersão nas obras individuais, seria necessário fundar uma IPA como dispositivo de regulação doutrinária: à exceção da obra fundadora, só deve haver monografias no campo psicanalítico (Milner, 1995, p. 17).

A sequência é também conhecida: a IPA se consolidou como um sistema doutrinário relativamente estável, estendendo-se, sobretudo, para os países de cultura anglo-saxônica. Porém, sabemos que, algumas décadas mais tarde, o campo psicanalítico, assim constituído, se desestabilizaria com a introdução de um novo enclave produzido por Jacques Lacan. Os motivos circunstanciais estão reportados: eles se iniciam com o julgamento de Lacan por parte do alto clero da IPA francesa, que o condenava pelo uso supostamente indevido das seções curtas. Inicialmente impedido de exercer suas atividades de analista didata, Lacan viria em seguida a perder o auditório do Hospital Saint'Anne, onde há uma década se realizava seu seminário semanal, para finalmente ser banido da Sociedade Francesa de Psicanálise, formalmente vinculada à IPA, em 1964. O campo psicanalítico se fechava para Lacan.

Mas deixemos, todavia, de lado o drama historiográfico da ex-comunicação. Retenhamos, somente, pelo momento, que Lacan, longe de ser o enfant rebelle que tantos imaginam, soube consentir com a monografia no período em que seu contexto o permitia. Ele não somente publicou diversos escritos monográficos, ao longo de sua vida, como também dirigiu uma importante revista - La psychanalyse - destinada a esse tipo de divulgação. Se Lacan consentiu em adotar tardiamente o desvio pela obra com a publicação dos Escritos, em 1966, foi por considerar que o contexto absorvera a psicanálise, transformando-a numa prática de gerenciamento de almas que não deixava mais lugar para o texto freudiano. A necessidade de um novo enclave se impunha. Uma vez mais seria preciso fazer-se obra; mais uma vez seria necessário, para retomar a expressão de Jean-Claude Milner, descer ao Aqueronte da cultura para reabrir espaço à doutrina psicanalítica.

Eu acreditava ver, contudo, uma singularidade nesse fazer-se obra, nessa descida ao Aqueronte de J. Lacan. O singular é que Lacan não constrói um escrito destinado a constituir-se como obra, como foi o caso da Traumdeutung freudiana, a qual seguia canonicamente as normas de revisão bibliográfica, recolocação do problema, estabelecimento de hipóteses e finalmente fundação de uma nova perspectiva para tratar o objeto assim constituído. Houve, a bem da verdade, o projeto de um livro fundador intitulado $O$ questionamento da psicanálise, que Lacan anunciou, sem, contudo, jamais levar essa ideia a cabo. Agradava-me, portanto, pensar que a obra de Lacan 
teria algo que se aproxima do ready-made de Marcel Duchamp. Assim como uma roda de bicicleta se converte em obra de arte pelo gesto calculado de deslocamento de sua posição na percepção social da mercadoria, transportando-a para a sala de exposição de um museu, o conjunto das monografias de Lacan parecia ter-se convertido em obra pelo simples gesto que as encadernar num volume intitulado Escritos. Um dado parecia, aliás, confirmar minha hipótese. Conforme nos relata J. Derrida, logo após publicar seus Escritos, o que Lacan temia não era que o conteúdo de seu livro fosse mal compreendido ou criticado. O seu principal temor, confidenciara ele a Derrida, era de que os Escritos se desencadernassem, que a costura da encadernação não suportasse o volume de textos, que a obra, enfim, perdesse sua unidade material e se espalhasse. Encantava-me interrogar esse fenômeno, para pensar a ideia do objeto-livro: como uma obra pode se constituir pelo simples gesto de encadernação de textos monográficos?

Mas minha hipótese não era exata, eu estava mais uma vez enganado. Por indicação de Gilson Iannini, coloquei-me a ler a pesquisa historiográfica de Jorge Baños Orellana, El escritorio de Lacan (Orellana, 1999), livro em que o autor nos demonstra que os Escritos nada tinham de um ready-made. Para preparar sua obra, Lacan não se contentou em transportar seus escritos monográficos para o interior de um volume encadernado. Ele, na verdade, se fechou em um hotel de Paris, onde permaneceu de março a outubro de 1966 relendo seus textos, reescrevendo-os e reexaminando as provas a serem enviadas para a edição final. Conforme os procedimentos de análise genética comentados por Baños Orellana, houve ali, durante esse período, um grande trabalho de transformação, destinado, sobretudo, a reelaborar o estilo texto final. Caberia, então, finalmente se perguntar por que motivo o trabalho sobre estilo se coloca, para Lacan, na transição da monografia para a obra fundadora.

Não me compete, decerto, dissertar aqui sobre o vasto problema do estilo em Jacques Lacan, sobretudo porque já existe, a esse respeito, uma referência inultrapassável: o livro de Gilson Iannini (2012), que já circula em sua segunda edição. A questão da estilística interessa-me tão somente como ponto sobre o qual se apreende a função unificante do autor, pois é dessa função unificante que depende, conforme dizia anteriormente, a unicidade da obra que diferencia a doutrina da multiplicidade geral da cultura, conferindo sua autonomia própria.

Por longo tempo se supôs que o autor da obra só seria apreensível no que ele tem de único, ou seja, naquilo que não se ensina, que somente ele poderia dizer através do estilo. Por isso, o estilo foi considerado pela crítica literária, representada sobretudo por Sainte-Beuve, como a ponte que nos conduz à unicidade do autor, revelando-o em sua intimidade. Havia uma espécie de devoção religiosa ao estilo, como se nele estivesse depositado o selo de garantia da obra. Se a obra é a expressão da unidade da doutrina, o autor seria sua função unificante, função do Um que só poderia ser captada a partir do estilo como marca do íntimo do autor em primeira pessoa na obra, cabendo à crítica literária o trabalho de seu desvelamento. Porém, Lacan já desconfiava dessa solução de Sainte-Beuve, que consiste em buscar na relação do autor com o estilo o princípio de unificação da 
obra. Seu programa de retorno a Freud é contemporâneo a um movimento crítico destinado a desconstruir precisamente, em sentido contrário, o culto ao autor como princípio de ordenação do texto. Atento a tudo o que se passava a sua volta, Lacan não desconhecia o surgimento, a partir dos anos 60, de uma corrente crítica representada, sobretudo, por M. Foucault e R. Barthes, que associava a importância conferida à figura do autor a uma visão individualista que concebe a obra nos termos burgueses da mercadoria e do patrimônio intelectual.

A começar por Barthes, em "A morte do autor", essa primazia dada ao personagem autoral não seria mais do que uma fiç̧ão historicamente datada do homem moderno, determinada tanto pela produção do prestígio pessoal do indivíduo com a ideologia da Reforma, quanto pela necessidade capitalista de unificar o produto do pensamento na forma mercadoria. Para Barthes, o autor deveria deixar de querer ordenar a unidade da obra, dando espaço a uma verdade impessoal, não comandada pela figura do eu. $O$ que conta é o que o leitor entende, e não o que o autor quis dizer.

Por sua vez, Foucault, quando dirige sua crítica à função do autor, também rejeita a ideia de um caráter natural e espontâneo dessa figura. A figura do autor nada mais é do que uma ficção moderna coextensiva a um modo de organização social e política surgido com o aparecimento do capitalismo, a partir do século XVI, ao qual se articulam tanto inovações tecnológicas - como a invenção da imprensa de Gutenberg -, quanto jurídico-penal - como a criação do códex e do direito autoral -, além de motivações tanto estéticas - como o mito romântico do gênio criador - quanto comerciais, como as estratégias de vendagem e as premiações. É nesse sentido que, ao meditar sobre a ideia do autor como princípio de unicidade da obra, Foucault nos revela seu constrangimento em se constituir ele próprio como autor, ao ser convocado a escrever o prefácio da $2^{a}$ edição de seu livro História da loucura. Foucault não queria se colocar como um autor que assume a autoridade do que enuncia, e se sentia particularmente incomodado por entender que no prefácio o autor é chamado a prescrever o sentido do que foi escrito. Por isso, ele nos conclama a tomar suas palavras não como proposições unificadas pela função autoritária do autor, mas acolhidas em sua fragmentação dispersa. Ao invés de ser respeitado pela autoridade de sua obra, Foucault pede para ser traído, deformado e esquecido. "Ao invés de tomar a palavra, gostaria de ser envolvido por ela e ser levado para além de todo começo possível [...]. Em vez de ser aquele de quem parte o discurso, eu seria, antes, ao acaso de seu desenrolar, o ponto de seu desaparecimento possível" e blá-bláblá...

A bem da verdade, por mais irresistível que seja a modéstia de Foucault ao despir-se da autoridade do autor, e apesar de todo respeito que temos por ele, ainda assim não podemos ceder a esse devaneio no campo da psicanálise. Estamos cientes do que ocorre quando se entrega o texto à apropriação irresponsável do leitor anônimo, conforme se viu na deturpação sofrida pela doutrina freudiana em sua recepção pelo contexto americano. Seja qual for a derrisão contemporânea do autor, não podemos deixar de interrogar, pelo menos no campo da psicanálise, sobre o que queriam 
dizer seus fundadores. Por isso, interessa-nos meditar sobre o que o próprio Lacan tinha a dizer sobre a obra que ele nos endereçava, em 1966.

Ora, o prefácio, já dizia constrangidamente Foucault, é o lugar em que o autor vem dizer como se organizam seus enunciados. O prefácio é o que, na obra, mais se assemelha a uma carta em que o autor tenta explicar ao leitor como ele gostaria de ser lido. Vale, então, salientar que, para nossa felicidade, Lacan nos endereçou, em seus Escritos, vários textos que funcionam como prefácios, dentre os quais gostaríamos de comentar o primeiro, curtíssimo e luminoso, que se coloca na porta de entrada de sua obra, intitulado "Abertura desta coletânea".

Lacan inicia esse texto a partir precisamente de um comentário sobre a questão do estilo, evocando a célebre fórmula endereçada por Buffon à Academia Francesa de Letras, por ocasião de seu laureado: o estilo é o próprio homem. É importante ali notar que no lugar em que o culto do estilo reverencia o personagem do autor, na figura do grande homem que ordena sua obra, Lacan nos convida a meditar sobre o que há de jocoso nessa figura do grande homem, representada por Buffon em seus trajes burlescos. Ao se colocar como autor de uma obra, Lacan não se deixa enredar por essa fantasia do grande homem. O ridículo dessa fantasia estilística do grande homem, aos olhos de Lacan, é não entender que o estilo depende não da eminência do autor, mas do laço que o constitui em seu endereçamento ao Outro, na forma da mensagem que Ihe retorna invertida. Nesse sentido, Lacan concebe o estilo não como uma entrega autoral da obra pronta a um leitor admirativo já presente, mas como meio de construção da obra através do leitor não dado, porém criado pelo seu endereçamento. A questão do estilo diz, portanto, respeito a quem vem a ser o leitor que ele faz existir.

Vale lembrar que a questão do "quem" é aqui particularmente sensível, uma vez que o estilo tradicionalmente se aborda, conforme vimos anteriormente, como marca do íntimo do autor em sua obra, na primeira pessoa. Mais importante do que a crítica de Foucault e de Barthes, a propósito da ideologia do culto ao autor, a grande subversão que interessa a Lacan vem não do Estruturalismo, mas do escritor Marcel Proust, grande herege que abalaria as fundações da igreja do estilo ao denunciar como impostura o trabalho de Sainte-Beuve2 . Para demonstrá-lo, Proust escreveria em 1919 os Pastiches et mélanges, conjunto hilário de versões pseudo-autorais de um mesmo assunto, onde se evidencia que a figura do estilo, supostamente advindo do íntimo na primeira pessoa do singular, na verdade não comporta indexação pronominal.

Os pastiches têm por tema comum o affaire Lemoine, notícia que circulou nos jornais nos anos de 1908 e 1909: um escroque chamado Henri Lemoine, que dizia ter descoberto o segredo da fabricação do diamante, recebeu uma soma considerável do Senhor Julius Werher, enganando-o com experimentos falseados. Os pastiches de Proust relatam o caso Lemoine no estilo de Balzac, Flaubert, Sainte-Beuve, Michelet, entre outros, seguindo uma narrativa indistinguível dos autores referidos. Mas os pastiches não são apenas um anedotário destinado a nos fazer rir. O que Proust ali questiona é justamente o quem referido ao estilo, mostrando que ele não comporta vínculo natural 
com a primeira pessoa, ao ser realocado na prosa romanesca de maneira indistinta. Mas o que acontecia quando Proust escrevia, sem que ele soubesse, provoca J.-C. Milner, é que no mesmo período em que ele redigia seus pastiches, a psicanálise já havia modificado a estrutura do íntimo, desfazendo sua indexação pronominal na primeira pessoa do singular. $\mathrm{O}$ inconsciente freudiano se encontra precisamente referido ao íntimo que desconhece a repartição pronominal entre o Ich, o $D u$ e o $E r$, permanecendo indeterminado no pronome neutro como Das $E s$.

Ciente dessa indeterminação pronominal do íntimo, a questão do estilo que interessa a Lacan não se coloca como marca inconfundível do íntimo do autor na primeira pessoa, conforme pretendia a tradição da crítica literária antes de Proust, mas como objeto indeterminado que afeta o leitor, transformando-o em sua intimidade (Iannini, 2012, p. 306). Tal indeterminação, aliás, vem a ser o que confere a eficácia do objeto carta no conto "A carta roubada", de Edgar Alan Poe: a carta endereçada à rainha, cujo conteúdo íntimo não é jamais explicitado pelo discurso que a cerca, afeta intimamente a todos que dela se apoderam. É em relação a esse ponto que cheguei à conclusão, anunciada no início de minha intervenção, de que a apropriação epistêmica da obra de Lacan não pode ser separada do testemunho de seu efeito sobre mim, como leitor. A experiência mostrou-me ser impossível ler diletantemente os Escritos, os Escritos não se dão a ler como objeto de curiosidade neutra de alguém que quer simplesmente aumentar o seu cabedal de cultura. Para acessá-los, foime necessário conservar na estante o objeto-livro inacessível, fascinante e estranho, até que suas páginas se abrissem vagarosamente a mim, no ritmo de minha própria transformação.

\section{Notas:}

${ }^{1}$ Esse texto é a transcrição de uma conferência apresentada em 2 de dezembro de 2016, por ocasião do Colóquio "50 anos dos Escritos de J. Lacan". Essa conferência, por sua vez, é a versão modificada e complementada de uma intervenção realizada quatro semanas antes - a convite de Márcia Rosa Luchina, coordenadora, na ocasião, das atividades da Biblioteca da Escola Brasileira de Psicanálise, Seção Minas, em evento intitulado "Os livros que lemos escondidos".

2 Indispensável ler, a esse respeito, J.-C. Milner, L'écrivain sans église. Recuperado de http://www.academia.edu/18563827/L\%C3\%A9crivain sans \%C3\%A9glise.

\section{Referências Bibliográficas}

Baños Orellana, J. (1999). El escritorio de Lacan. Buenos Aires: Oficio Analítico. Recuperado de https://psiligapsicanalise.files.wordpress.com/2014/09/jorge-b-orellana-el-escritorio-delacan.pdf.

Barthes, R. (1993). 6. Le bruissement de la langue (pp. 61-75). Paris: Seuil.

Derrida, J. (1991). Pour l'amour de Lacan. Lacan avec les philosophes (pp. 397-420). Paris: Albin Michel. 
Foucault, M. (1969). Qu'est-ce qu'un auteur? Bulletin de la Sociéte française de philosophie, LXIV (pp. 73-95). Paris: Vrin.

Iannini, G. (2012). Estilo e verdade em J. Lacan. Belo Horizonte: Autêntica.

Lacan, J. (1966). Écrits. Paris: Seuil.

Milner, J.-C. L'écrivain sans église. Recuperado de

http://www.academia.edu/18563827/L\%C3\%A9crivain sans \%C3\%A9glise.

Milner, J.-C. (1995). L'CEuvre Claire. Paris: Seuil.

Proust, M. (1992). Pastiches et mélanges. Paris: Gallimard.

Citacão/Citation: Teixeira, A. (mai. a out. 2017). Experiências de saber e testemunho íntimo no encontro com os Escritos de Jacques Lacan. Revista aSEPHallus de Orientação Lacaniana, 12(24), 81-91. Disponível em www.isepol.com/asephallus. doi: 10.17852/1809-709x.2019v11n24p81-91.

Editor do artigo: Tania Coelho dos Santos.

Recebido/Received: 24/09/2017 / 09/24/2017.

Aceito/Accepted: 09/10/2017 / 10/09/2017.

Copyright: (C) 2013 Associação Núcleo Sephora de Pesquisa sobre o moderno e o contemporâneo. Este é um artigo de livre acesso, que permite uso irrestrito, distribuição e reprodução em qualquer meio, desde que o autor e a fonte sejam citados/This is an open-access article, which permites unrestricted use, distribution, and reproduction in any medium, provided the author and source are credited. 